\title{
Fixed costs matter even when the costs are sunk
}

\author{
Jurjen Kamphorst ${ }^{\mathrm{a}, \mathrm{b}, *}$, Ewa Mendys-Kamphorst ${ }^{\mathrm{c}}$, Bastian Westbrock ${ }^{\mathrm{d}}$ \\ a Erasmus University Rotterdam, The Netherlands \\ ${ }^{\mathrm{b}}$ Tinbergen Institute, The Netherlands \\ ${ }^{\mathrm{c}} \mathrm{CEG}$, The Netherlands \\ ${ }^{\mathrm{d}}$ Fernuniversität Hagen, Germany
}

\section{A R T I C L E I N F O}

\section{Article history:}

Received 4 June 2020

Received in revised form 14 July 2020

Accepted 17 July 2020

Available online 23 July 2020

\section{JEL classification:}

D42

L11

Keywords:

Sunk costs

Liquidity constraints

Switching costs

Pricing

\begin{abstract}
A B S T R A C T
How firms set prices is key to understanding markets. Standard economics dictates that the fixed costs of a firm should not affect its prices. Nonetheless, it is common practice for firms to raise their prices after a fixed costs increase. We show that firms are correct in doing so if two ubiquitous conditions apply: (i) future profits increase in current sales and (ii) firms are liquidity-constrained.
\end{abstract}

(C) 2020 Published by Elsevier B.V.

\section{Introduction}

Economics textbooks teach us that the fixed costs of a firm should not affect its prices and quantities. Yet, there is considerable evidence that firms incorporate fixed costs in their pricing decisions (e.g., Govindarijian and Anthony, 1983; Shim and Sudit, 1995).

In this note, we show that firms can be right in doing so. The basic idea is as follows. Consider a firm for which a higher output today means more profits in the future, for instance because of switching costs. Consequently, the lifetime profit of the firm is maximized at a lower price than the one that maximizes the firm's current profit. Suppose further that the firm is liquidityconstrained: it goes bankrupt if it incurs a loss during the current period. The firm is, now, hit by a fixed costs shock. If its costs increase to the point where the lifetime profit-maximizing price would lead to a loss, it is optimal for the firm to raise its price. This shifts profits from the future to the current period, and helps the firm to survive.

The two key conditions behind our argument are thus that (i) future profits increase in current sales and (ii) the firm is liquidity-constrained. If either assumption is violated, there is no impact of fixed costs on prices. We believe, however, that both

\footnotetext{
* Corresponding author.

E-mail addresses: kamphorst@ese.eur.nl (J. Kamphorst),

emendys@ceg-europe.com (E. Mendys-Kamphorst),

bastian.westbrock@fernuni-hagen.de (B. Westbrock).
}

assumptions are valid in many contexts. There are many reasons why future profits may increase in current sales, such as switching costs, brand loyalty, or learning by doing (e.g., Samuelson and Zeckhauser, 1988). An even larger body of empirical work has demonstrated that the access to liquid assets can significantly constrain the operational decisions of a firm (e.g., Borenstein and Rose, 1995; Chevalier, 1995; Banerjee and Duflo, 2014).

Theories with a link between fixed costs and prices can be found at several places in the economics literature. The earliest theories date back to at least Baumol (1971). He showed that if fixed costs are not yet sunk, then an increase of these costs can cause the firm to choose a lower capacity and output, and a higher price. ${ }^{1}$ More recent explanations have been offered by Brander and Lewis (1986), Thépot and Netzer (2008), Janssen (2006), and Janssen and Karamychev (2007). Nevertheless, there are at least two important differences between these theories and ours. First, in contrast to Baumol (1971), fixed costs affect prices in our model even when they are sunk. Second, in contrast to all the other theories, our argument is not dependent on demand uncertainty, risk aversion, or the presence of multiple firms. We thus offer a concise explanation for why fixed costs may affect prices under quite general circumstances. ${ }^{2}$

\footnotetext{
1 Cabral and Riordan (1994) also consider avoidable fixed costs in a setting where, like in our model, higher current demand increases future profits. They, however, focus on competition and predatory incentives.

2 Although this is the first formalization of the explanation, we should mention that the basic argument can already be found in Borenstein and Rose
} 
The following Sections 2-4 present our basic argument. In Section 5, we show that the argument carries over to the case of soft liquidity constraints, where a firm pays higher interest rates over its debt when its debt increases. Section 6 concludes.

\section{The basic model}

Our model is a simplified version of the ones in Chevalier and Scharfstein (1996) and Klemperer (1995, Section 5.2), where liquidity-constrained firms sell to consumers with switching costs.

Consider a monopolist, active in two periods. In each period $t \in\{1,2\}$, the monopolist chooses the quantity $Q_{t}$ and earns the profit $\pi_{t}$ that is equal to operational profits, $\pi_{t}^{o}$, minus fixed costs, $F_{t}$. Key to our story, the second-period profit depends positively on the first-period output,

$\frac{\partial \pi_{2}^{\circ}\left(Q_{1}, Q_{2}\right)}{\partial Q_{1}}>0$.

Also, the firm goes bankrupt unless it makes at least a profit of $B$ in $t=1$ (where $B$ may be negative). The lifetime profit function of the firm is thus given by

$\Pi\left(Q_{1}, Q_{2}\right)= \begin{cases}\pi_{1}^{o}\left(Q_{1}\right)-F_{1}+\delta\left[\pi_{2}^{o}\left(Q_{1}, Q_{2}\right)-F_{2}\right] & \text { if } \pi_{1} \geq B, \\ 0 & \text { otherwise, }\end{cases}$

where $0<\delta<1$ denotes the discount factor on profits made in $t=2$.

Our plan is to show that the monopolist may rationally increase its price after an increase of $F_{1}$. To keep things simple, we therefore assume that the profit function has the following common properties. Each per-period profit function is twice differentiable, strictly concave, and single-peaked in that period's quantity. Hence, there exists a unique, positive $Q_{1}^{*}$ that maximizes first-period profits. Similarly, for any $Q_{1}$ there exists a unique $Q_{2}^{*}\left(Q_{1}\right)$ that maximizes second-period profits. In addition, the unconstrained lifetime profit function, $\pi_{1}^{o}\left(Q_{1}\right)-F_{1}+\delta\left[\pi_{2}^{o}\left(Q_{1}, Q_{2}\right)-\right.$ $\left.F_{2}\right]$, is twice differentiable, strictly concave, and single-peaked at a unique, positive pair $\left(Q_{1}^{* *}, Q_{2}^{* *}\right)$, where obviously $Q_{2}^{* *}=$ $Q_{2}^{*}\left(Q_{1}^{* *}\right)$.

Our final assumptions restrict the attention to the most interesting case. First, there exists a $Q_{1}$ such that $\pi_{1}^{o}\left(Q_{1}\right)-F_{1}>B$. This ensures that the firm can survive the first period if it wants to. Second, there exists a pair $\left(Q_{1}, Q_{2}\right)$ such that $\Pi\left(Q_{1}, Q_{2}\right)>0$. This ensures that the firm wants to survive if it can. Third, there exists a $Q_{2}>0$ such that $\pi_{2}^{\circ}\left(Q_{1}^{*}, Q_{2}\right)-F_{2}>0$. This ensures that the firm produces in the second period if it survives.

\section{Optimal strategy}

In $t=2$, the firm maximizes current profits, given that it is still in business. The first-order condition gives

$Q_{2}^{*}\left(Q_{1}\right): \frac{\partial \pi_{2}^{o}\left(Q_{1}, Q_{2}^{*}\right)}{\partial Q_{2}}=0$.

In $t=1$, the firm maximizes total discounted profits. Let $Q_{1}^{B}$ be the highest quantity such that $\pi_{1}^{o}\left(Q_{1}\right)-F_{1} \geq B .^{3}$ By the strict concavity of $\pi_{1}^{o}\left(Q_{1}\right)$, it follows that for any $Q_{1}>Q_{1}^{B}$ the firm will go bankrupt. Moreover, because the firm can survive the first period if it wants to, we have $Q_{1}^{B}>Q_{1}^{*}$.

(1995) and Chevalier (1995). Our net contribution is thus the formalization, which the literature failed to pick up on. Our second contribution is to show that the link between fixed costs and prices also holds up when the liquidity constraint is soft.

3 When $B=0, Q_{1}^{B}$ is thus the break-even output, where the price $P\left(Q_{1}^{B}\right)$ is equal to the firm's average total cost.
Next, we show that also the optimal, non-liquidity-constrained quantity satisfies $Q_{1}^{* *}>Q_{1}^{*}$. By the Envelope Theorem, $Q_{1}^{* *}$ solves

$$
\frac{\partial \Pi\left(Q_{1}^{* *}, Q_{2}^{*}\left(Q_{1}^{* *}\right)\right)}{\partial Q_{1}}=0 \Leftrightarrow \frac{\partial \pi_{1}^{o}\left(Q_{1}^{* *}\right)}{\partial Q_{1}}+\delta \frac{\partial \pi_{2}^{o}\left(Q_{1}^{* *}\right)}{\partial Q_{1}}=0 .
$$

As $Q_{1}^{*}$ solves $\partial \pi_{1}^{o}\left(Q_{1}^{*}\right) / \partial Q_{1}=0$, and because $\partial \pi_{2}^{o}\left(Q_{1}\right) / \partial Q_{1}>0$ for all $Q_{1}$, we immediately arrive at the claim. Intuitively, $Q_{1}^{* *}$ exceeds $Q_{1}^{*}$ because marginally increasing $Q_{1}$ at $Q_{1}^{*}$ does not affect first-period profits but does increase second-period profits. At $Q_{1}^{* *}$, the loss in first-period profits by marginally increasing $Q_{1}$ exactly offsets the increase in the discounted second-period profits.

It follows from the above that the liquidity constraint is binding if and only if $Q_{1}^{B}<Q_{1}^{* *}$. Therefore, the optimal first-period quantity, $Q_{1}^{\max }$, is given by $Q_{1}^{\max }=Q_{1}^{* *}$ if $Q_{1}^{* *} \leq Q_{1}^{B}$, and $Q_{1}^{\max }=$ $Q_{1}^{B}$ otherwise.

\section{The role of fixed costs}

Knowing $Q_{1}^{\max }$, we now consider how it is affected by a fixed costs increase. Let the fixed costs increase from $F_{1}$ to $F_{1}^{\prime}$ and let $Q_{1}^{B^{\prime}}$ denote the highest quantity such that $\pi_{1}^{o}\left(Q_{1}^{B^{\prime}}\right)-F_{1}^{\prime} \geq B$. Of course, $Q_{1}^{B}>Q_{1}^{B^{\prime}}$ because first-period profits decline in $Q_{1}$ for any $Q_{1}>Q_{1}^{*}$. There are three possible outcomes:

First, $Q_{1}^{* *} \leq Q_{1}^{B^{\prime}}$. In this case, the optimal quantity $Q_{1}^{\max }$ was and remains $Q_{1}^{* *}$. The liquidity constraint still has no bite, and the firm can choose its unconstrained first-best quantity. This is the standard result, where fixed costs have no impact on the optimal quantity or price.

Second, fixed costs increase so much that bankruptcy becomes unavoidable. This is the case when $\pi_{1}^{o}\left(Q_{1}^{*}\right)-F_{1}^{\prime}<B$.

Third, $Q_{1}^{*} \leq Q_{1}^{B^{\prime}}<Q_{1}^{* *}$. This is the case we are interested in. Here, the increase in the fixed costs tightens the liquidity constraint, reduces the quantity to $Q_{1}^{B^{\prime}}$, and therefore increases the price. This third case is thus consistent with the claim that a fixed cost increase might necessitate an increase in prices for a firm to stay in business. Lifetime profits are reduced for two reasons. The first is the higher fixed costs, and the second is that the firm cannot afford to invest as much in future profits as before.

\section{Soft liquidity constraints}

Above, we assumed a hard liquidity constraint. The firm went bankrupt if it failed to make sufficient profits. Here, we consider the more common case of a soft liquidity constraint: a firm pays higher interest rates if its debt increases. Also in this case, a fixed costs increase can result in a higher price.

As before, let $Q_{1}^{*}$ maximize first-period profits, $\partial \pi_{1}^{o}\left(Q_{1}^{*}\right) / \partial Q_{1}=$ 0 , and let $Q_{2}^{*}\left(Q_{1}\right)$ maximize second-period profits, $\partial \pi_{2}^{o}\left(Q_{1}, Q_{2}^{*}\right) /$ $\partial Q_{2}=0$. Let $D_{t}$ be the firm's outstanding debt at the beginning of period $t \in\{1,2\}$. This debt needs to be refinanced at the start of the next period . $D_{1}$ is exogenously given. $D_{2}$ depends, in contrast, on $D_{1}$ and the first period's profits in the following way:

$D_{2}\left(D_{1}, \pi_{1}\right)=\left[1+r_{1}\right] D_{1}+F_{1}-\pi_{1}^{o}$,

where $r_{t} \equiv r\left(D_{t}\right)$ denotes the interest rate that is due at the end of period $t$. That interest rate shall increase in the outstanding debt, $\partial r\left(D_{t}\right) / \partial D_{t}>0$. The firm's lifetime profit function is thus given by

$\Pi\left(Q_{1}, Q_{2}\right)=\pi_{1}^{o}\left(Q_{1}\right)-F_{1}-r_{1} D_{1}+\delta\left[\pi_{2}^{o}\left(Q_{1}, Q_{2}\right)-F_{2}-r_{2} D_{2}\right]$.

Consider, now, the first-period quantity that maximizes lifetime profits, $Q_{1}^{\max }$. As in the case of a hard liquidity constraint, $Q_{1}^{\max }>Q_{1}^{*}$. To see this, consider $Q_{1}=Q_{1}^{*}$. Then, selling 
marginally more does not affect current profits. Therefore, selling marginally more does not increase $D_{2}$. Because future profits do increase in current sales, $\partial \pi_{2}^{o}\left(Q_{1}\right) / \partial Q_{1}>0$, however, it follows that the optimal first-period quantity is strictly larger than $Q_{1}^{*}$, so $\partial \Pi\left(Q_{1}^{*}, Q_{2}^{*}\left(Q_{1}^{*}\right)\right) / \partial Q_{1}>0$ and $Q_{1}^{\max }>Q_{1}^{*}$.

In particular, it follows from the first-order condition of (1), that $Q_{1}^{\max }$ satisfies

$$
\begin{aligned}
& \frac{\partial}{\partial Q_{1}} \pi_{2}^{o}\left(Q_{1}^{\max }, Q_{2}^{*}\left(Q_{1}^{\max }\right)\right) \\
& =-\frac{1}{\delta} \frac{\partial \pi_{1}^{o}}{\partial Q_{1}}+\frac{\partial D_{2}}{\partial \pi_{1}^{o}} \frac{\partial \pi_{1}^{o}}{\partial Q_{1}} r_{2}+\frac{\partial r_{2}}{\partial D_{2}} \frac{\partial D_{2}}{\partial \pi_{1}^{o}} \frac{\partial \pi_{1}^{o}}{\partial Q_{1}} D_{2} .
\end{aligned}
$$

On the left-hand side, we see the benefit of selling marginally more, namely the positive impact on future operational profits. On the right-hand side, we see the costs of selling marginally more, namely (i) the reduction in current profits; (ii) the interest that has to be paid on the additional first-period losses; and (iii) the additional payments on the outstanding debt at the end of period two due to higher interest rates.

Fixed costs affect the optimal strategy through effects (ii) and (iii). Ceteris paribus, higher current fixed costs imply higher future debt and therefore higher future interest rates. The higher the interest rate, the more a firm pays per unit of debt, and the less willing it is to take on additional debt by lowering current profits. This is effect (ii). Effect (iii) comprises two separate effects. The first effect is simple. Any increase in interest rate is more costly the higher the debt is. Therefore, the firm is less willing to incur additional debt after a fixed costs increase. However, if the responsiveness of the interest rate to debt changes as the debt increases, $\partial^{2} r_{2} / \partial\left(D_{2}\right)^{2} \neq 0$, then this responsiveness is a consideration as well. It matters to the firm if a unit of additional debt has a large effect on its interest rate or a small effect. The larger the effect is, the larger is $\partial r_{2} / \partial D_{2}$, and the more costly an additional unit of debt is. Combining this with the earlier effects, it follows that the firm may in fact choose a more competitive strategy if fixed costs increase, but only if $\partial^{2} r_{2} / \partial\left(D_{2}\right)^{2}$ is negative enough. Hence, $\partial^{2} r_{2} / \partial\left(D_{2}\right)^{2} \geq 0$ is a sufficient condition for the price to strictly increase as a result of higher fixed costs.

We now show this formally: let $\Pi^{\prime}$ denote the first-order derivative of $\Pi$ with respect to $Q_{1}$ (see Eq. (2)). Because the firm optimally adjusts to any fixed costs change, Eq. (2) holds for any $F_{1}$. Therefore, the total derivative of (2) with respect to $F_{1}$ and $Q_{1}$ is equal to zero:

$$
\frac{\partial \Pi^{\prime}}{\partial F_{1}} d F_{1}+\frac{\partial \Pi^{\prime}}{\partial Q_{1}} d Q_{1}=0 \Leftrightarrow \frac{d Q_{1}}{d F_{1}}=-\frac{\frac{\partial \Pi^{\prime}}{\partial F_{1}}}{\frac{\partial \Pi^{\prime}}{\partial Q_{1}}}
$$

When will an increase in fixed costs decrease the optimal output, so $d Q 1 / d F 1<0$ ? We know that $\partial \Pi^{\prime} / \partial Q_{1}<0$ because $\Pi$ is concave in $Q_{1}$. Therefore, the relevant condition is $\partial \Pi^{\prime} / \partial F_{1}<0$, or equivalently

$$
\begin{aligned}
& -\delta\left[\frac{\partial D_{2}}{\partial \pi_{1}^{o}} \frac{\partial \pi_{1}^{o}}{\partial Q_{1}}\right] \frac{\partial r_{2}}{\partial D_{2}} \frac{\partial D_{2}}{\partial F_{1}}-\delta\left[\frac{\partial r_{2}}{\partial D_{2}} \frac{\partial D_{2}}{\partial \pi_{1}^{o}} \frac{\partial \pi_{1}^{o}}{\partial Q_{1}}\right] \frac{\partial D_{2}}{\partial F_{1}} \\
& -\delta \frac{\partial^{2} r_{2}}{\partial\left[D_{2}\right)^{2}} \frac{\partial D_{2}}{\partial F_{1}}\left[\frac{\partial D_{2}}{\partial \pi_{1}^{o}} \frac{\partial \pi_{1}^{o}}{\partial Q_{1}} D_{2}\right]<0 .
\end{aligned}
$$

By $\partial D_{2} / \partial \pi_{1}^{o}=-1$ and $\partial D_{2} / \partial F_{1}=1$, we obtain

$2 \frac{\partial r_{2}}{\partial D_{2}} \frac{\partial \pi_{1}^{o}}{\partial Q_{1}}+\frac{\partial^{2} r_{2}}{\partial\left(D_{2}\right)^{2}} \frac{\partial \pi_{1}^{o}}{\partial Q_{1}} D_{2}<0$.

Moreover, since $\partial \pi_{1}^{o} / \partial Q_{1}<0$ is negative, while $\partial r_{2} / \partial D_{2}$ and $D_{2}$ are positive, we get $\partial \Pi^{\prime} / \partial F_{1}<0$ if and only if

$\frac{\partial^{2} r_{2}}{\partial\left(D_{2}\right)^{2}}>-\frac{2}{D_{2}} \frac{\partial r_{2}}{\partial D_{2}}$.

As the right-hand side is negative, it follows that $\partial^{2} r_{2} / \partial\left(D_{2}\right)^{2} \geq 0$ is a sufficient condition for $\partial \Pi^{\prime} / \partial F_{1}<0$.

This shows that our results do not require a hard liquidity constraint. As long as interest rates depend positively on a firm's debt and $\partial^{2} r_{2} / \partial\left(D_{2}\right)^{2}$ is not 'too negative', higher fixed costs lead to higher prices.

\section{Conclusion}

In this note, we bridge a long-standing gap between standard economic theory, according to which a firm's fixed costs should not affect its prices, and business practice, where many firms do take fixed costs into account when setting prices. In contrast to earlier theories on the topic, ours also applies both in case of sunk costs and in the absence of competition.

\section{References}

Banerjee, A.V., Duflo, E., 2014. Do firms want to borrow more? Testing credit constraints using a directed lending program. Rev. Econom. Stud. 81 (2), 572-607.

Baumol, W.J., 1971. Optimal depreciation policy: pricing the products of durable assets. Bell J. Econ. Manage. Sci. 2 (2), 638-656.

Borenstein, S., Rose, N.L., 1995. Bankruptcy and pricing behavior in US airline markets. Amer. Econ. Rev. 85 (2), 397-402.

Brander, J.A., Lewis, T.R., 1986. Oligopoly and financial structure: The limited liability effect. Amer. Econ. Rev. 76 (5), 956-970.

Cabral, L.M., Riordan, M.H., 1994. The learning curve, market dominance, and predatory pricing. Econometrica 62 (5), 1115-1140.

Chevalier, J.A., 1995. Do LBO supermarkets charge more? An empirical analysis of the effects of LBOs on supermarket pricing. J. Finance 50 (4), 1095-1112.

Chevalier, J.A., Scharfstein, D.S., 1996. Capital-market imperfections and countercyclical markups: theory and evidence. Amer. Econ. Rev. 86 (4), 703-725.

Govindarijian, V., Anthony, R.N., 1983. How firms use cost data in pricing decisions. Manag. Account. 65 (1), 30-31.

Janssen, M.C., 2006. Auctions as coordination devices. Eur. Econ. Rev. 50 (3), $517-532$.

Janssen, M.C., Karamychev, V.A., 2007. Selection effects in auctions for monopoly rights. J. Econom. Theory 134 (1), 576-582.

Klemperer, P., 1995. Competition when consumers have switching costs: An overview with applications to industrial organization, macroeconomics, and international trade. Rev. Econom. Stud. 62 (4), 515-539.

Samuelson, W., Zeckhauser, R., 1988. Status quo bias in decision making. J. Risk Uncertain. 1 (1), 7-59.

Shim, E., Sudit, E.F., 1995. How manufacturers price products. Strateg. Finance $76(8), 37$

Thépot, J., Netzer, J.-L., 2008. On the optimality of the full-cost pricing. J. Econ. Behav. Organ. 68 (1), 282-292. 